had an oesophageal biopsy. Histology findings for these 48 cases are reported in table 1. $21(19.4 \%)$ patients with no visible lesion had further investigation after endoscopy: 8 (7.4\%) barium swallow, 9 (8.3\%) CT and 3 (2.8\%) manometry.

\begin{tabular}{lll} 
Abstract PTH-018 Table 1 & & \\
\hline & Number & $\%$ \\
\hline Normal & 23 & 41.8 \\
GORD & 22 & 40.0 \\
EOE & 4 & 7.3 \\
Barretts (BE) & 5 & 9.1 \\
Oesophageal & 1 & 1.8 \\
ulcer & & \\
\hline
\end{tabular}

Final diagnosis for all patients who had no structural lesion (6 months after initial OGD): 64 (59.3\%) had no diagnosis, 26 (24.1\%) had GORD, 5 (4.6\%) had a dysmotility disorder, 4 (3.7\%) had EoE and 6 (5.6\%) had BE.

Conclusion Two thirds of patients had no visible cause of dysphagia identified at endoscopy, but only half of these patients had oesophageal biopsies taken as recommended by the BSG. Where there were taken the most common finding was normal histology (41.8\%), while $40.0 \%$ had GORD and only $7.3 \%$ had EOE.

Nearly $60 \%$ of patients with dysphagia who are referred for endoscopy have no formal diagnosis made 6 months after initial endoscopy.

\section{PTH-019 'MISSED' OESOPHAGO- GASTRIC CANCERS ON GASTROSCOPY: ARE WE REALLY MISSING THEM ALL?}

Subashini Chandrapalan*, Jessica Green, Francisco Perez, Ahmed Mukhtar, Deepak Kejariwal. University Hospital Of North Durham, Durham, UK

\subsection{6/gutjnl-2018-BSGAbstracts.41}

Introduction Oesophago-Gastric (OG) cancer usually present late with consequent poor prognosis. The failure to detect early stage OG cancer at endoscopy may contribute to poor prognosis. A recent meta-analysis reported miss rates of $11.3 \%$ for OG cancers at endoscopy up to 3 years prior to diagnosis (1). We looked at our data in the Trust to quantify how often opportunities to diagnose cancer at an earlier stage are missed.

Method A retrospective review was carried out, on the medical records of newly diagnosed gastro-oesophageal cancer patients at County Durham and Darlington NHS Trust between the period 01/08/2014 - 31/07/2017. The data was extracted on patients who had standard light gastroscopy within a period of 3 years prior to the diagnosis. Endoscopic images were reviewed by a panel of 3 consultant gastroenterologists.

Results A total of 181 patients were diagnosed as having gastro-oesophageal cancers during the study period, of whom 12 had gastroscopy within three years. Amongst them, 3 had gastroscopy within one year prior to the diagnosis. The index endoscopy was performed by consultant gastroenterologist in 6 patients, nurse endoscopist in 4 and others in 2 patients.

The overall incidence of cancers in patients who had gastroscopy within 3 years and 1 year were $6.6 \%$ and $1.6 \%$ respectively. Amongst those, 8 were oesophageal, 3 were gastric and 1 of them was junctional cancer. Endoscopic photo documentation was fully retrievable for 6 patients who had endoscopy within 3 years and the review confirmed normal looking mucosa at the anatomical area concerned. (50\%).

Conclusion Our study shows, incidence of the oesophageal cancer was high in comparison to gastric or junctional tumours for those who had gastroscopy within 3 years prior to the diagnosis. The normal endoscopic photo documentation in $50 \%$ of the patients, suggests interval cancers rather than 'missed' cancers. This raises suspicion on whether we are increasingly dealing with rapidly progressing tumours as suggested by emerging evidence that many cancers develop rapidly by punctuated and catastrophic genome evolution (2). Serial photographic documentation of important anatomical landmarks in accordance with latest BSG guidance (3) and further studies on interval cancers are important for future cancer interception.

\section{PTH-020 ENDOSCOPIC MUCOSAL RESECTION: EVALUATION OF A SINGLE CENTRE OUTCOME}

Subashini Chandrapalan*, Tracy Wood, James Crosbie, John Painter. City Hospital Sunderland, Sunderland, UK

\subsection{6/gutjnl-2018-BSGAbstracts.42}

Background EMR has been well accepted as one of the management options for superficial colorectal tumours requiring minimal invasion, better patient tolerance and significantly lower morbidity compared to surgery. However, lesions $\geq 20$ mm can be tricky.

Method Retrospective medical record analysis was performed for a period of 24 months between Jan 2015 - Dec 2016. The data was collected on patient demographics, polyp characteristics, complications and follow up endoscopy at the 3 months and 12 months intervals where applicable.

Results A total of 212 patients had 264 procedures. The mean age of the population was 68 . All of the procedures were performed by experienced endoscopists using hot/cold snare and Methylene blue/Volplex solution. 22 (8\%) of all polypectomies were $\geq 40 \mathrm{~mm}$ in size. The rate of complications in accordance with polyp size and colonic sites are illustrated below (table 1 and 2).

The perforation was managed with endoclips and required a day of admission. The immediate bleeding had been managed with clipping \pm adrenaline injection. The overall 30 days mortality was zero. 9 (4\%) patients had prophylactic endoclips.

\begin{tabular}{|c|c|c|c|c|}
\hline Complications & $\begin{array}{l}\text { Polyp } \\
\text { size }<20 \mathrm{~mm} \\
(\mathrm{n}, \%)\end{array}$ & $\begin{array}{l}\text { Polyp size } 20- \\
39 \mathrm{~mm} \\
(\mathrm{n}, \%)\end{array}$ & $\begin{array}{l}\text { Polyp } \\
\text { size } \geq 40 \mathrm{~mm} \\
(n, \%)\end{array}$ & $\begin{array}{l}\text { Total } \\
\text { (Percentage) } \\
(n, \%)\end{array}$ \\
\hline $\begin{array}{l}\text { Immediate } \\
\text { bleeding }\end{array}$ & $8(206,4 \%)$ & $1(36,3 \%)$ & $2(22,9 \%)$ & $11(264,5 \%)$ \\
\hline $\begin{array}{l}\text { Delayed } \\
\text { bleeding }\end{array}$ & 0 & 0 & 0 & 0 \\
\hline Perforation & 0 & $1(36,3 \%)$ & 0 & $1(264,0.4 \%)$ \\
\hline $\begin{array}{l}\text { Recurrence at } \\
3 / 12\end{array}$ & 0 & 0 & $3(22,14 \%)$ & $3(264,1 \%)$ \\
\hline $\begin{array}{l}\text { Recurrence } 12 / \\
12\end{array}$ & 0 & 0 & $1(12,8 \%)$ & $1(109,0.9 \%$ \\
\hline
\end{tabular}

